\title{
HYBRID TECHNOLOGY OF REDUCTION OF NITROGEN OXIDES (NOx) IN EXHAUST GASES; PART 2 - NUMERICAL MODEL OF PILOT SCALE REGENERATIVE ROTARY AIR HEATER (RAH) RETROFITED WITH SELECTIVE CATALYST REDUCTION (SCR) MODULES
}

\author{
Andrzej Kwiczala ${ }^{1, *}$, Robert Wejkowski ${ }^{2}$ \\ ${ }^{1}$ SBB ENERGY SA, ul. Łowicka 1, 45-324 Opole, Poland \\ ${ }^{2}$ Silesian University of Technology, Institute of Power Engineering and Turbomachinery, ul. \\ Konarskiego 20B, 44-100 Gliwice, Poland
}

\begin{abstract}
This article exhibits the results of the analysis performed to verify the effectiveness of the hybrid flue gas denitrification system (herein referred to as HDS) which involved the retrofitting for selective catalytic reduction (SCR) material into a regenerative rotary air heater (RAH). A numerical model corresponding to the actual pilot scale RAH operating conditions was developed. The ultimate intent of the numerical model is to provide a platform where the technology can be implemented on full scale air preheaters. The numerical analysis performed on the pilot scale HDS installation showed a 3\% decrease in heat exchange efficiency in the exchanger. This decrease was significantly minimized by the use of blades adjusting the distribution of flue gases entering the RAH. This means that the exhaust gas temperature at the exchanger outlet increased by $4^{\circ} \mathrm{C}$, which corresponds to an average of $0.3 \%$ increase in the boiler outlet loss. It was also recognized that the air temperature was reduced by $8^{\circ} \mathrm{C}$, which does not translate into significant changes in boiler performance parameters. other boiler operating parameters in a noticeable way during operation.
\end{abstract}

\section{Introduction}

Current European NOx emission directives for power boilers burning solid fuels with a total nominal power delivered in fuel above $100 \mathrm{MW}$ requires NOx emissions in exhaust flue gas at the level not exceeding $200 \mathrm{mg} / \mathrm{m}_{\mathrm{n}}^{3}$ for flue gas with $6 \%$ oxygen content [1].

\footnotetext{
*Corresponding author: a.kwiczala@,sbbenergy.com
} 
This directive requires the majority of existing facilities to conduct a comprehensive optimization of the combustion process along with the parallel use of SCR and / or Selective Non-Catalytic Reduction (SNCR) system installations. An additional challenge for modern power production facilities is more stringent emission standards to a level of $65-150 \mathrm{mg} / \mathrm{m}^{3}$ to existing facilities that must be achieved in less than two years (before $04.2021 \mathrm{r}$.).

This imposes the necessity to develop new technologies to reduce the emission of nitrogen oxides, or modify existing ones to achieve the required level of reduction. Solutions combining the primary methods of reducing $\mathrm{NO}_{\mathrm{x}}$ together with SNCR and SCR are available in the market, but normally include the SCR section as a separate element in the later sections of the boiler flue gas pass. The SCR system generally requires structural changes to the boiler superstructure or the necessity to develop additional space around it, thereby increasing the capital costs of such an installation. For this reason, the implementation of SCR involved solutions in existing facilities is problematic for energy facility owners.

Following the market needs, SBB ENERGY SA, in the framework of the pilot research project "Hybrid technology denitrification in power boilers", in cooperation with the Department of Boilers and Steam Generators Institute of Power Machines and Equipment Silesian University of Technology, has undertaken to develop a hybrid technology called flue gas denitrification HDS (Hybrid Denitrification System as earlier referred to) based on a combination of primary methods to reduce NOx emissions with the SNCR installation in the combustion chamber and the SCR installation, located in the regenerative rotary air heater (RAH).

The HDS system involves the modernization of RAH using high thermal transfer efficiency element replacement for better heat transfer, which results in shortening the required active length of the exchanger. In this way, the RAH has liberated space in which catalyst material can be installed, thus transforming a section of the RAH to a NOx SCR module. Placing catalyst inserts in the RAH significantly reduces the amount of investment outlays and eliminates the need to develop additional space for conventional SCR installations. It also allows the reduction of flue gas pressure loss compared to that of traditional SCR systems, thus reducing the operating costs of the installation itself.

Locating catalyst material in a RAH has been the basis of research for over 30 years [2-9].

However, erosion problems of metal sheets coated with catalyst made the dissemination of this idea in coal-fired boilers impossible [3]. Problems with using steel plates as catalyst substrate brought about the introduction of monolithic ceramic catalysts $[4,5,6]$. Further extensive research is performed in order to develop new catalysts, like a mercury-capturing catalyst [7]. Catalysts with active carbon as a substrate for SCR have been also presented $[8,9]$.

This solution has been tested in full scale at a Swedish power plant, resulting in a $90 \%$ reduction in NOx emissions in parallel with the partial oxidation of ammonia carried by the exhaust gas from the SNCR installation [10]. Unfortunately, the relatively strong phenomenon of erosion of metal substructure coated with a catalyst 
material stopped the implementation process of this technology in coal-fired boilers, due to the necessity of their frequent replacement [11]. For this reason, the subject of this project also included the selection of catalytic inserts so as to minimize the negative impact of erosion on the operation of the installation while maintaining NOx reduction at the appropriate level.

This article presents the results of the second stage of this project work, involving the numerical modelling of the pilot scale RAH. Validation of the model was made on the basis of measurements carried out on pilot, namely: boundary temperatures, pressure and flow measurements. The model utilizes results from earlier work involving the pressure drop, flow resistance and turbulence occurring during the flow of the medium through the catalytic cartridge [12].

The main objective of the research was to verify the effectiveness of the proposed solution and to create a preliminary numerical model corresponding to the actual working conditions of a pilot scale regenerative rotary air heater. It is intended to utilize the resultant numerical model to develop full scale HDS RAH initiatives.

\section{Methodology}

\subsection{Description of the RAH Pilot Assembly}

Tests were performed on the RAH pilot assembly, the dimensions of which were reduced accordingly, maintaining the flow conditions - gas stream velocity, stream distribution, etc. The main parameters of the pilot assembly are summarized in Table 1.

The diameter of the exchanger is approximately $1 \mathrm{~m}$, and its height $-0.9 \mathrm{~m}$ (Figure 1). The heat exchanger was divided into two parts - a cold and hot end. The cold end heating elements are made of steel profiled sheets in the form of a basket, while the hot end of the exchanger is an SCR module.

The rotor is divided in cross-section into 9 sections, 7 being active - the flue gas flows through 4 of the active sections and the air flows through 3 sections. Due to the possibility of thermal expansion or deformation of the rotor during operation, the structure of the pilot assembly includes a system for suspending radial leaves separating the rotor, allowing them to be adjusted by means of adjustment tendons. The rotor is powered by a gear/motor built on the lower end of the shaft, which is braced by a supporting structure, similar to the housing of the pilot assembly. The change in rotational speed takes place by adjusting the frequency on the inverter from which the geared motor is powered.

The air and flue gas streams flow counter-currently through the rotating exchanger elements. As the heat exchange assembly rotates, heat is absorbed by the elements resident in the hot medium (flue gas). As these same elements rotate into the cold medium stream (air) the heat is expelled thus providing the heat exchange function 


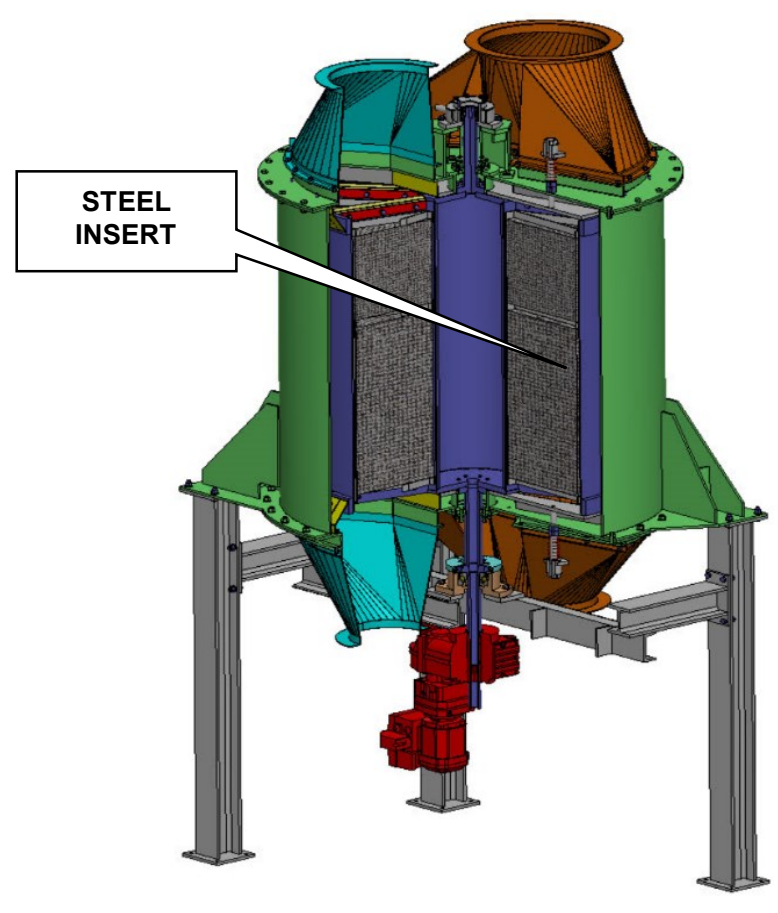

Fig. 1. General RAH scheme

Table 1 Main parameters of the RAH pilot scale station

\begin{tabular}{|c|c|}
\hline Parameter & Value of \\
\hline Rotor diameter & $1030 \mathrm{~mm}$ \\
\hline Height of the rotor without shafts & $1210 \mathrm{~mm}$ \\
\hline Rotor weight & $527 \mathrm{~kg}$ \\
\hline Total height of heating elements & $900 \mathrm{~mm}$ \\
\hline Number of radial baffles & 9 \\
\hline Speed of rotation & $0,5-7 \mathrm{rpm}$ \\
\hline Total heating surface & $149 \mathrm{~m}^{2}$ \\
\hline
\end{tabular}


Fig. 2 and Fig. 3 presents the RAH pilot assembly with the system of ducts supplying various media to the RAH, the combustion chamber, the chimney and the fans (both air and flue gas fans).

The air for tests is taken from the environment using an air fan controlled by an inverter. Pressure, temperature and air flow are measured downstream of the fan at the RAH inlet.

The flue gas flows into the exchanger through a duct from the furnace chamber. The source of fumes is a retort burner with power in the $100-200 \mathrm{~kW}$ range, burning eco-pea type coal with a calorific value of approx. $27 \mathrm{MJ} / \mathrm{kg}$, integrated with a combustion chamber without a water jacket, made of heat-resistant brickwork. The retort burner is equipped with a coal reservoir, a screw feeder and an air fan. Due to the lack of heat removal from the exhaust gases in the chamber, for the purpose of gas temperature regulation, the recirculation of cooled exhaust gases from downstream of the RAH is utilized. This type of solution allows for the composition and dusting of gas similar to that of realistic conditions occurring in industrial power boilers.

The parameters of the exhaust gas (flow, temperature, pressure, composition) are measured both at the inlet and at the outlet of the exchanger. The gases are pulled in by an exhaust fan adapted to work in high dust.

The necessity to mount the elbows on the inlet and exhaust air ducts caused inhomogeneity of the flow of media to the exchanger, which was compensated for by mounting flow straighteners ensuring the smoothest possible inflow of gases to the exchanger element.

In order to investigate the nature of heat transfer inside the exchanger, a temperature measurement system was installed involving 9 measurement points, located in 3 sections of the exchanger (lower, middle and upper parts) and in 3 radial distances (closer to the center of the exchanger's rotation axis, in the vicinity of the maximum diameter and between these points). Measurements of temperature, pressure and flow were performed on-line during the operation of the pilot assembly.

Due to the pressure difference between the media involved, the typical phenomenon is the air leak to the exhaust gases exists. Its magnitude of leakage was determined on the basis of the flow measurement of both factors at the inlet and outlet of the exchanger. 


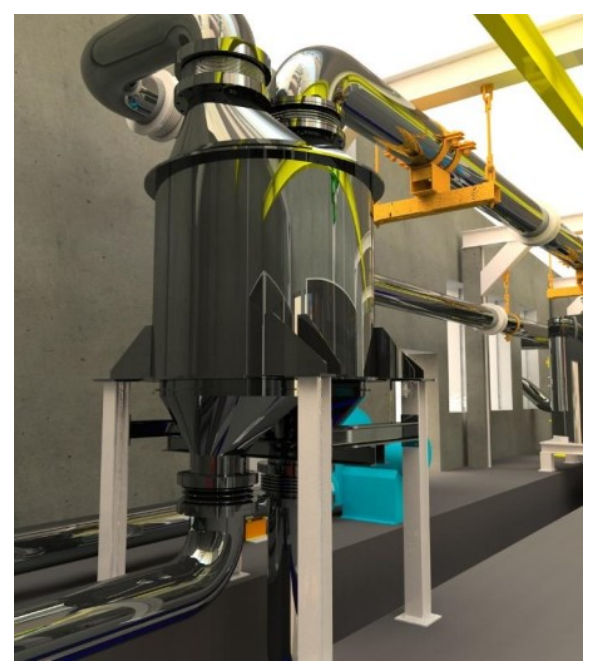

Fig. 2. Pilot scale RAH

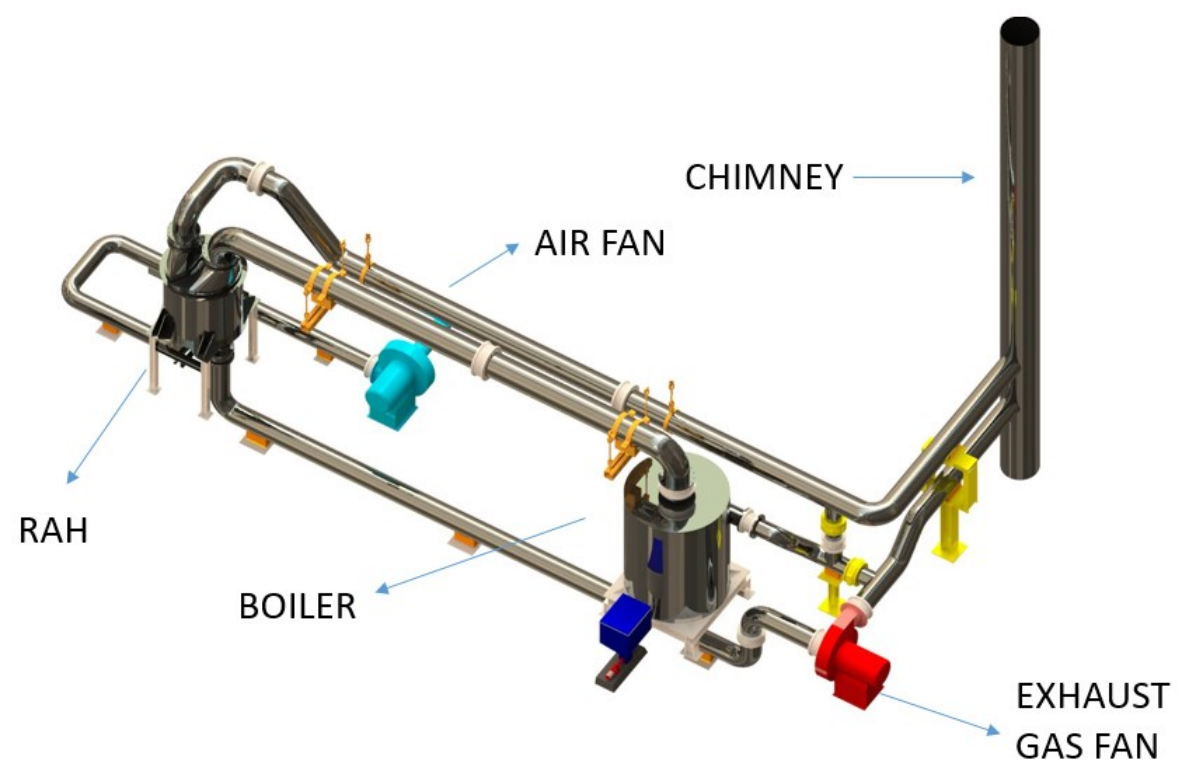

Fig. 3. Assembly for pilot scale RAH 
The laboratory stand is also equipped with a control system controlled by means of dedicated software enabling the analysis of online measurement values. Location of temperature measurements T1 - T11 has been described on Figure 4.

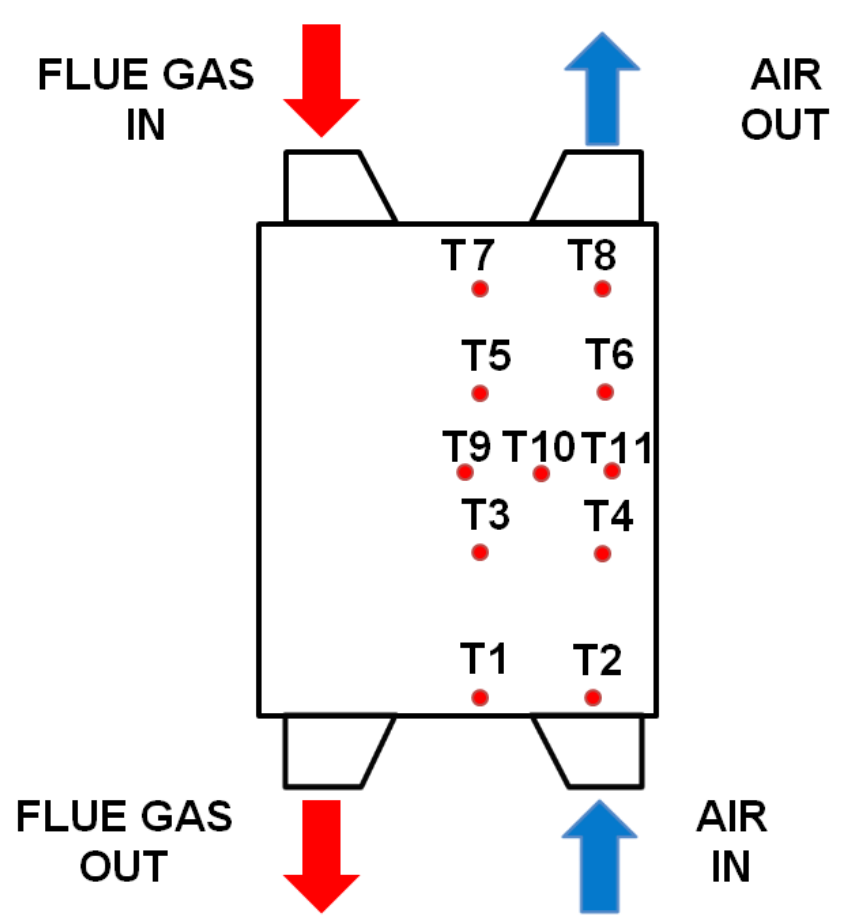

Fig. 4 Location of temperature measurements T1 - T11

\subsection{Numerical simulation}

Installation of catalytic inserts in the upper part of the regenerative exchanger means that the inserts will most certainly be exposed to the phenomenon of abrasion due to the high concentration of fly ash in the flue gas. In order to reduce the harmfulness of this phenomenon, it is possible to apply remedial measures in the form of exhaust flow guides, as well as a flow straighteners located directly above the upper part of the cartridges. An additional effect of unifying the inflow of exhaust gases and dust to the exchanger results in an increase in the efficiency of heat conduction. 
The most effective way to obtain information on the protection of the installed cartridges against erosion and to optimize the heat transfer process is to use the results of CFD calculations.

The aim of the numerical analysis was also:

- to determination of heat exchange coefficients for existing steel inserts;

- to determination of heat exchange coefficients for new catalytic cartridges;

- to execute a numerical analysis that will allow the design of further optimized combinations of steel and catalytic inserts;

- to determinate of the decrease in heat exchange efficiency.

Based on the results of several dozens of measurement series carried out on a pilot research bench, a numerical model was created that allows a formulation of RAH 's operation and increase in the efficiency of its work. The calculations provided in this article present the results of CFD analysis for RAH operation in a standard or reference configuration (only with steel inserts) as well as in combination of steel and catalytic inserts.

The geometry of the regenerative model of the exhaust flue gas-air exchanger as a result of discretization was divided into a grid consisting of 1.5 million structural and non-structural elements (Figure 5).

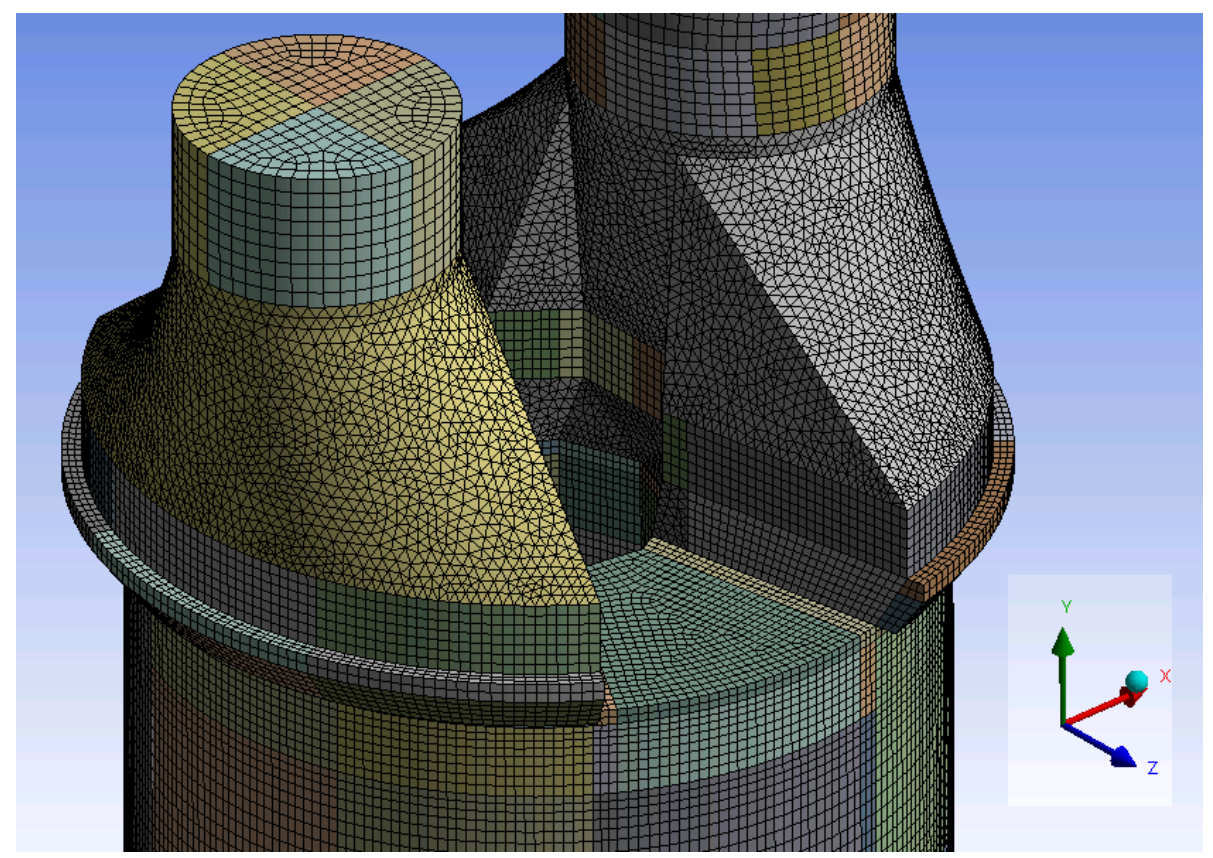

Fig. 5. Computational grid created as a result of discretization consisting of 1.5 million structural and unstructured elements 
Qualitative coefficient of skewness for the calculated model indicates that only 20 elements are characterized by a quality worse than fit 0.75 - Fig. 6 .

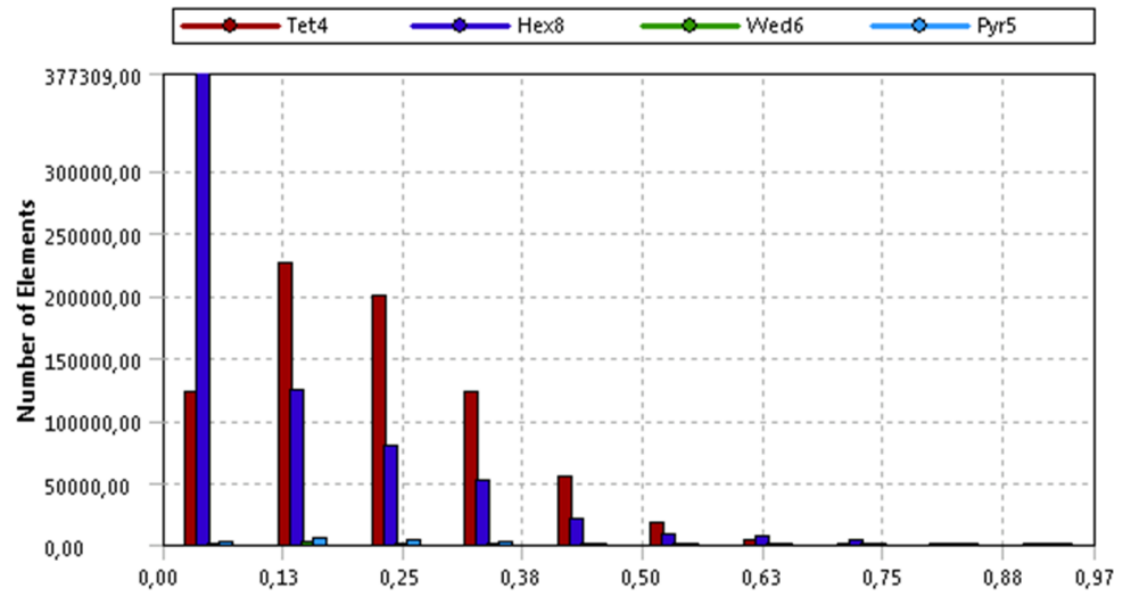

Fig. 6. Qualitative coefficient of skewness of the grid

\section{RESULTS}

\subsection{Reference physical tests}

One of the risks to the operation of catalytic inserts is the variability of the temperature of the medium flowing through its surface. Too large temperature differences can lead to cracking of both the frame and catalytic material, which can result in damage to the cartridges.

Due to the planned implementation of the HDS installation involving the extension of existing SNCR installation, it was reasonable to conduct reference measurements and calculations based on real RAH operating conditions.

The laboratory reference measurement was carried out based on measurement data taken from a typical Polish Combined Heat and Power plants. The temperature of flue gas entering the $\mathrm{RAH}$ is $301{ }^{\circ} \mathrm{C}$ and exhaust gas outlet temperature is equal to $134^{\circ} \mathrm{C}$. The averaged values of reference measurements on the test bench are shown in Figure 4.

Inside the exchanger are a total of 11 thermocouples attached to the load-bearing structure of the inserts. During operation of the RAH the thermocouples continuously change their position with the rotor rotation with the frequency set by 
the operator. Measured temperature values for the reference variant discussed herein are shown in Fig. 5.

Thermocouples, numbered from $\mathrm{T} 1$ to $\mathrm{T} 9$, measure the temperature of the heat exchanger inserts while thermocouples from T10 and T11 measure the temperature of air and exhaust gases. The $\mathrm{x}$-axis indicates the angle of rotation while the $\mathrm{y}$-axis is the average of the temperature measured during steady-state operation.

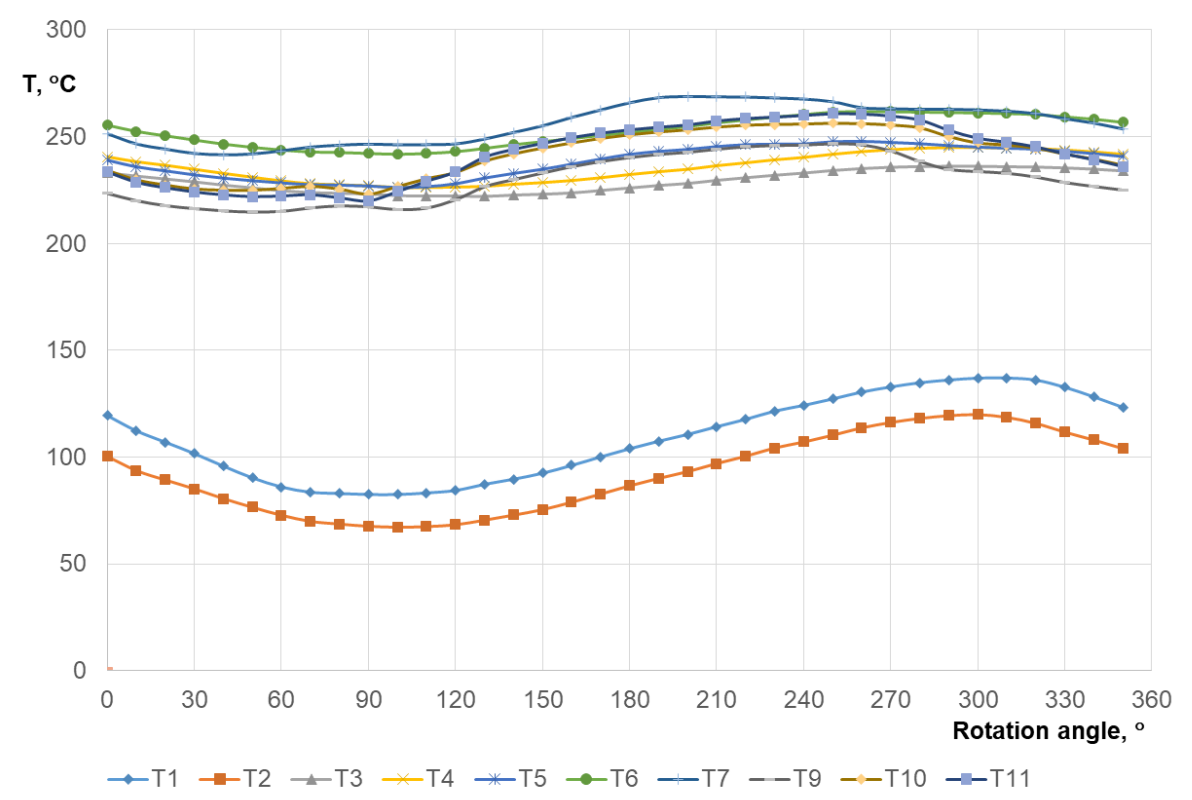

Fig. 7. Temperature measurement from thermocouples located inside RAH structure

The thermocouples located at the cold end of RAH are exposed to the greatest temperature difference. From the reference measurements shown, these variations are up to $55^{\circ} \mathrm{C}$. The temperature of the cartridges located in the upper part of the exchanger (hot end) varied only by $15^{\circ} \mathrm{C}$. This means that the most suitable location of the catalytic inserts is in the hot end where the most stable temperature field exists.

\subsection{Results of CFD calculation}

\subsubsection{Numerical simulation - velocity}

Fig. 7 and Fig. 8 show the results of calculations made in the ANSYS Fluent program in the form of contours of the exhaust velocity distribution in the cross- 
section by RAH and flue gas duct. The results of calculations carried out for the reference measurements for the variant with flow straighteners are shown in Fig. 8 and the variant without these flow devices is shown in Fig. 9.
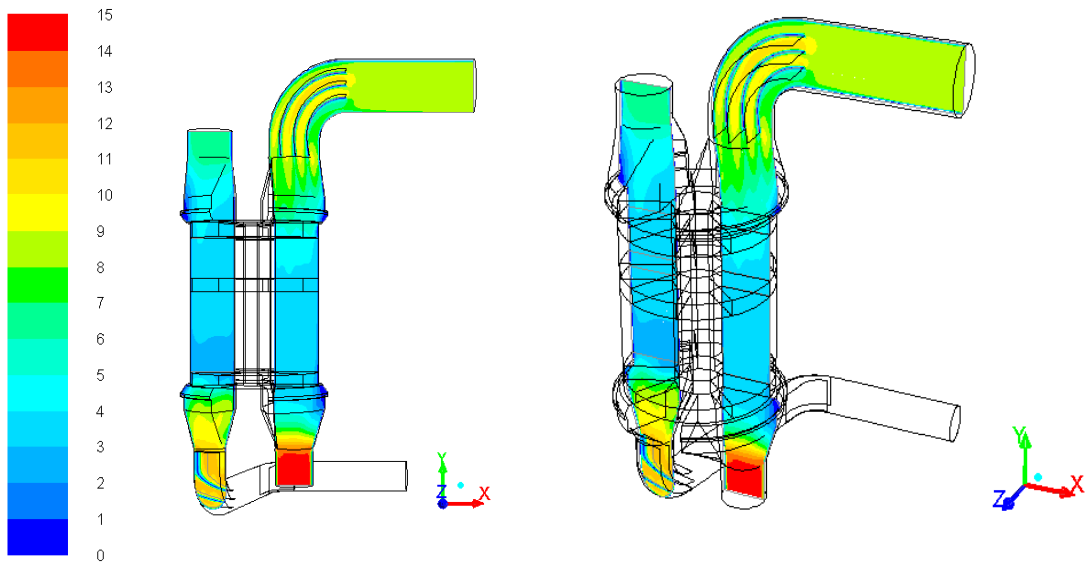

Fig. 8 The distribution of flue gas velocity at the inlet of the Air Heater with flue gas flow straighteners, $\mathrm{m} / \mathrm{s}$; left side - side view; right side - isometric view
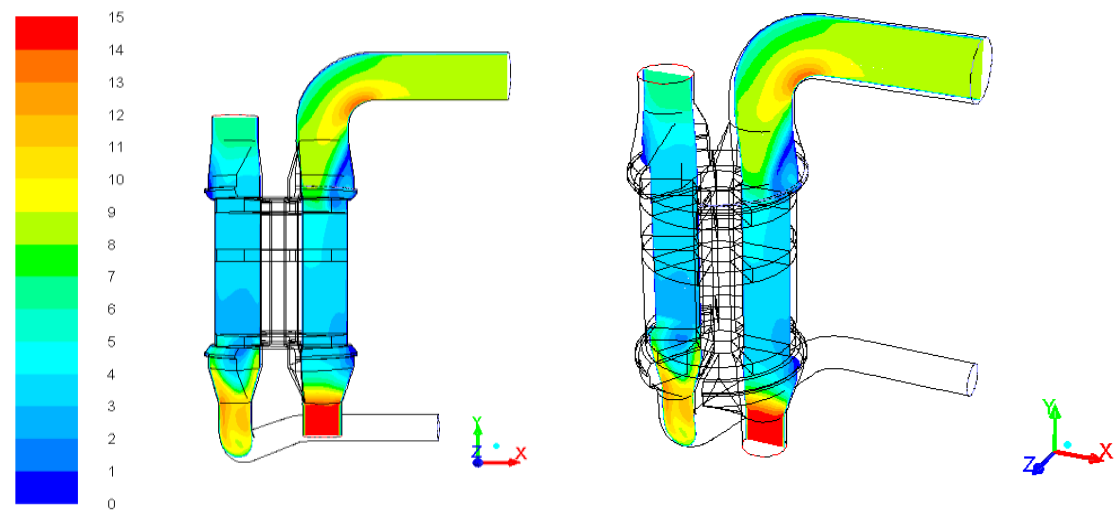

Fig. 9. The distribution of flue gas stream velocity at the Air Heater inlet without flue gas flow straighteners, $\mathrm{m} / \mathrm{s}$; left side - side view; right side - isometric view.

Numerical comparative analysis carried out indicates a $2.5 \%$ increase in efficiency of the exchanger when the inflow of exhaust gases is aligned to the air 
heater elements. An additional significant advantage of the solution which takes into account the influence of the shape of flue gas ducts on the RAH operation is a more uniform temperature distribution in the exchanger which in practice will reduce the phenomenon of ash adsorption in the exchanger.

\subsubsection{Precise calculation of heat transfer coefficients}

Calculations were carried out with the help of the ANSYS Fluent software. The software enabled precise mapping of the heat exchange process in RAH thanks to the implementation of the UDF procedure. The proprietary program code created by SBB Energy S.A. allows calculations to be carried out that take into account the unevenness of the fluid velocity distribution (flue gas, air) flowing through the material layer to the heat exchange coefficient. Fig. 10 shows the locally calculated heat transfer coefficient from the fluid to the catalytic inserts in RAH.
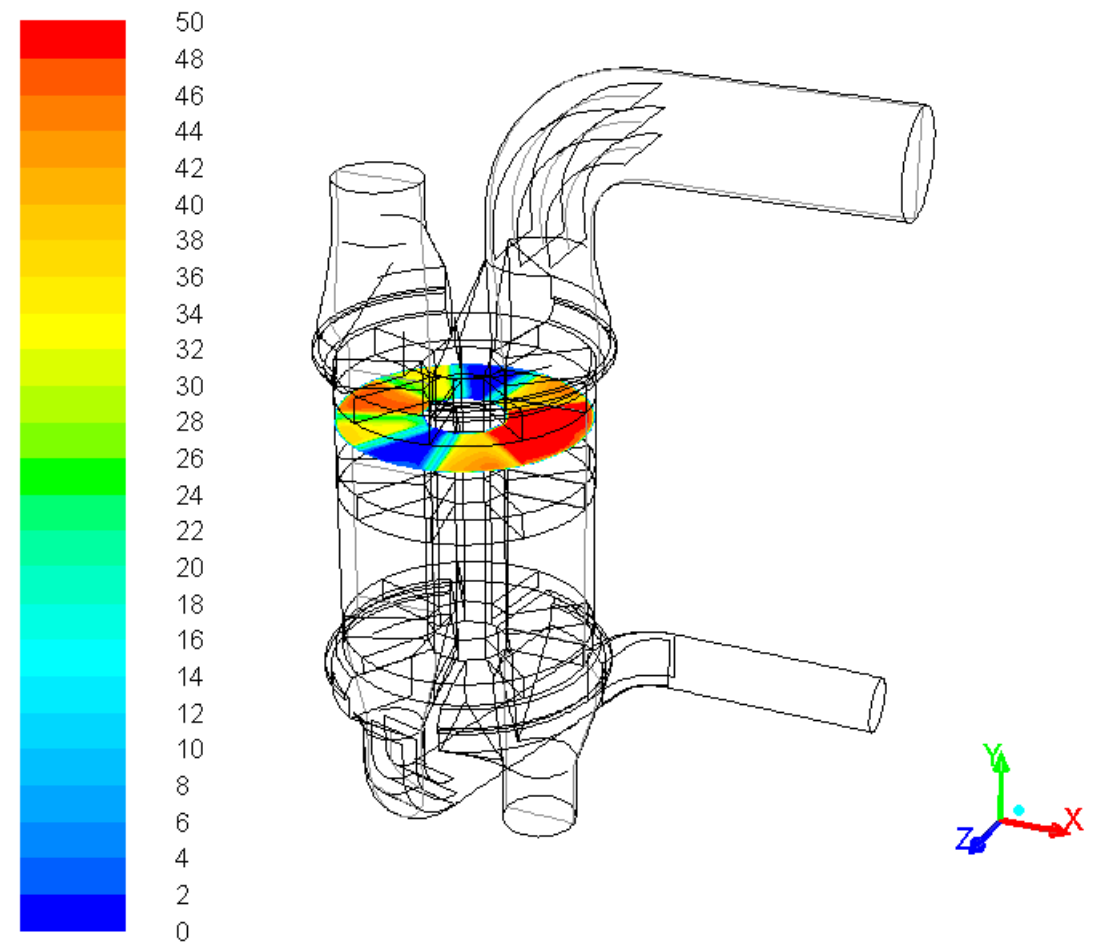

Fig. 10. Distribution of the heat transfer coefficient $\left[\mathrm{W} / \mathrm{m}^{2} \cdot \mathrm{K}\right]$ inside the RAH material 


\subsubsection{The impact of the assembly of catalytic inserts on heat transfer}

The biggest challenge that occurred during the implementation of the hybrid NOx reduction method was not the deterioration of boiler operational conditions and minimizing the energy loss from the boiler. The catalyst materials have a lower density, conductivity and heat capacity than standard regenerative cartridges. Fig. 11 shows the numerical contours obtained in numerical modeling and table 1 the results of measurements, the left side - the reference variant; right side - HDS variant.
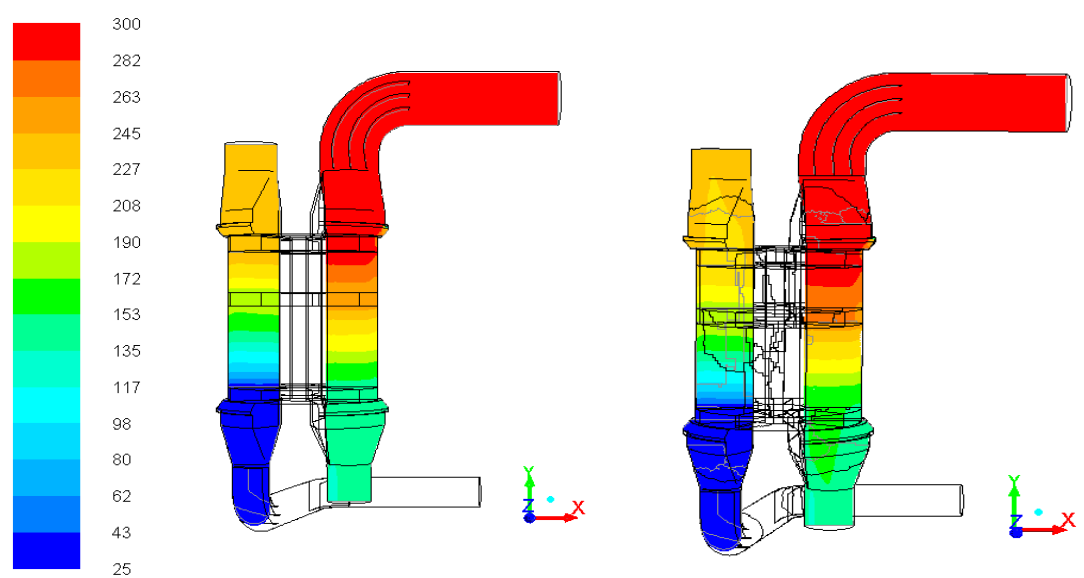

Fig. 11. Resultant temperature contours, ${ }^{\circ} \mathrm{C}$; left side - reference variant; right side - HDS variant

Both calculations and reference measurements showed a similar 3\% decrease in exchange efficiency in the Airheater. This means that for the calculations made, the outlet temperature of flue gas increased by $4^{\circ} \mathrm{C}$ while the temperature of heated air decreased by $8^{\circ} \mathrm{C}$. 
Table 2. Obtained measurements of inlet / outlet temperatures and exchanger efficiency for the base variant and modernization of HDS

\begin{tabular}{|c|c|c|}
\hline Type of inserts & Steel & Catalytic / Steel \\
\hline & \multicolumn{2}{|c|}{ Temperature, ${ }^{\circ} \mathrm{C}$} \\
\hline Air intake & 24.5 & 24.5 \\
\hline Gas inlet & 301.2 & 301.2 \\
\hline Air outlet & 241.7 & 233.5 \\
\hline Exhaust gas outlet & 134.2 & 138.2 \\
\hline Efficiency ROPP & $78.5 \%$ & $75.53 \%$ \\
\hline
\end{tabular}

\section{Conclusion}

The idea to use a NOx reduction catalyst as part of a regenerative heat exchangers has been considered in Polish and world power industry for many years. The main reasons why no one previously dared to implement ceramic inserts were: lack of catalyst resistance to abrasion; catalyst weight; and poor reactivity of available catalysts at temperatures below $350^{\circ} \mathrm{C}$. Suppliers of catalytic materials have been improving their products in recent years making them lightweight, resistant to harsh working conditions and improved their reactivity at temperatures lower than 350 deg. C.

The test stand constructed as part of the HDS project enables testing of ceramic catalytic and standard steel inserts of any type or configuration.

The implementation of catalytic inserts inside the RAH requires precise selection of the shape and composition of the inserts that are involved in the transfer of heat. During the design process of the HDS system, the variable environment to which the cartridges may be exposed to and consideration of the non-catalytic component replacement for cartridges with higher heat transfer capacity should be considered.

The pilot and laboratory tests carried out show a 3\% decrease in RAH efficiency when the hybrid method of reducing nitrogen oxides in flue gases is applied. The decrease in efficiency translates into a $4{ }^{\circ} \mathrm{C}$ increase in the temperature of flue gases and $8^{\circ} \mathrm{C}$ a drop in the temperature of the combustion air. This causes a boiler efficiency drop by approximately $0.3 \%$. The change in temperature of heated air and exhaust gases does not change other boiler operational parameters significantly.

\section{Acknowledgments}

Research was carried out as part of the project "Hybrid denitrification technology for fired boilers in power boilers" co-financed under the Regional Operational Program 
of the Opolskie Voivodship for 2014-2020. Priority Axis 1 Innovations in the economy; Measure 1.1 Innovation in enterprises, carried out by SBB ENERGY SA in cooperation with the Institute of Power Engineering and Turbomachinery of the Silesian University of Technology.

\section{References}

1 Directive 2010/75 / EU of the European Parliament and of the Council of 24 November 2010 on industrial emissions (integrated pollution prevention and control)

2 M. Kotter., HG. Lintz., T. Turek.: Katalytische Stickoxid-Reduktion in einem rotierenden Wärmeübertrager. Chem. -Ing. Tech. 1992 64(5), str. 446-448.

3 K. Veser.: Regenerativ-Wärmetauscher in der Umwelttechnik, Betriebserfarungen mit dem Gasvorwärmer an Naßentschwefelungsanlagen, mit Pilot-Anlagen denoxgerechter Luft- und Gasvorwärmer an Entstickungsanlagen und Anordnungskriterien für solche; Entwicklungsstand des DENOXLuvo/DENOX-Gavo. VGB Kraftwerkstechnik 66 H12 1986.

4. M. Kułażynski, M. Pronobis, A. Walewski, R. Wejkowski and W. Wojnar, Selektywna redukcja katalityczna (SCR) tlenków azotu w regeneracyjnym obrotowym podgrzewaczu powietrza (Selective catalytic reduction SCRin rotary air heater - in Polish), Rynek Energii 6, 2008, 82-87.

5 M. Pronobis, R. Wejkowski and M. Kułażyński, NOx control for pulverised coal fired boilers, Pol J Environ Stud 18 (1B), 2009, 183-187.

6. R Wejkowski, W Wojnar: Selective catalytic reduction in a rotary air heater (RAH-SCR), Energy 145, 2017, 367-373

7. R. Stollea, H. Koesera and H. Gutberlet, Oxidation and reduction of mercury by SCR DeNOx catalysts under flue gas conditions in coal fired power plants, Appl Catal B Environ 144, 2014, 486-497.

8. G. Marbán and A.B. Fuertes, Low-temperature SCR of NOx with NH3 over NomexTM rejects-based activated carbon fibre composite-supported manganese oxides: part II. Effect of procedures for impregnation and active phase formation, Appl Catal B 34, 2001, 55-71.

9. J. Trawczynski and M. Kulazynski, Active carbon monoliths as catalyst supports for SCR (selective catalytic reduction) of NOx with ammonia, In: 8th International Conference on Coal Science, Oviedo, Spain, Sep 1995.

10 ScandeNOx Combined SNCR and SCR, http://www.scandenox.dk/kontakt1 (on-line: 09.09.2018 r.).

11 MJ. Frank., H. Gutberlet., J. Brandenstein.: Betrieb von RauchgasEntstickungsanlagen mit DENOX-Katalysatoren. VGB PowerTech 4/2006, str. 72-77.

12 A. Kwiczała., R. Wejkowski., K Jagodzińska., S Kalisz.: Hybrid technology of flue gas denitrification system. Part 1. - Preliminary studies of flow turbulence 
and pressure drop in the elements of rotary air heater baskets. $5^{\text {th }}$ International Conference on Contemporary Problems of Thermal Engineering CPOTE 2018, 18-21.09.2018, Gliwice, Polska. 